\title{
Talk to The Plates, Curtailing Transmission of Bacteria in The Air by Wearing Masks
}

\author{
Robert L Sautter* \\ Principal Consultant RL Sautter Consulting LLC, Lancaster SC, USA \\ *Corresponding author: Robert L Sautter, Primary Consultant RL Sautter Consulting LLC, Lancaster SC, USA.. \\ To Cite This Article: Robert L Sautter, Talk to The Plates, Curtailing Transmission of Bacteria in The Air by Wearing Masks. Am J Biomed Sci \& \\ Res. 2021 - 11(5). AJBSR.MS.ID.001671. DOI: 10.34297/AJBSR.2021.11.001671.
}

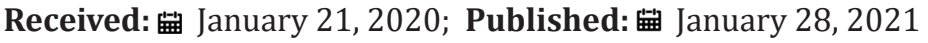

\begin{abstract}
Airborne bacteria come from many different sources. Hospital employees as well as the general public may harbor microorganisms and disseminate them through the air. It is well known that coughing and sneezing produce droplet nuclei that harbor organisms for long periods of time in the air. However, few people realize that talking will disseminate microorganisms as well. During this pandemic, it is clear that wearing a mask can protect people from possible infection and transmission of the virus as well as infectious bacteria. In the operating room, masks are worn so that the spread of microorganisms will be minimized. During this pandemic, it is mandated by CDC to wear a mask when interacting with other people and to maintain a 6-foot social distancing [1,2]. The purpose of this study was to compare the microorganisms that would be disseminated by reading a childhood nursery rhyme. This study will demonstrate how bacteria can disseminate by talking without a mask and could very well also transmit viral particles. The results of the study were kept anonymous and shared with the voluntary study.
\end{abstract}

\section{Commentary}

Droplet nuclei are produced by a variety of methods such as: sneezing, coughing, talking and other means of creating aerosols. The droplet nuclei are about 1 to 5 microns in diameter, and can remain suspended in the air for several hours. A sneeze can generate 40,000 droplet nuclei. Talking for 5 minutes may generate 3000 and singing can generate 3000 droplet nuclei in a single minute. Also, talking and using certain letters such as (p) will generate higher droplet nuclei as compared to other letters used in words. By far, Sneezing generates the most droplet nuclei (up to tens of thousands), which can spread to individuals 6-10 feet away. Therefore, most likely a mask can prevent spreading bacteria and viruses through normal contact between people [2-6].

\section{Methods}

a) Have personnel hold a trypticase soy agar plate with $5 \%$ sheep blood 12 inches from their mouth.

b) Have each of them recite "Peter Piper" for 1 minute, see below.

c) A total of 17 people were sampled by reading the rhyme within 12 inches from their mouth. Label the plates from 1-17 and transport back to the microbiology laboratory. d) Choose two people and have them hold an open plate 12 inches from their mouths and do not talk as well as doing the same thing without a mask and reciting the rhyme.

e) Incubate the plates for $48 \mathrm{hrs}$ at $35 \mathrm{C}$ in 5\% CO2 in air.

f) Empirically identify the isolates and quantify the colonies growing.

g) Photograph the plates.

h) Share results of cultures with the testing personnel.

i) Numerous bacteria grew from the experiment. Below are "talk plates" from 2 different volunteers.

\section{Nursery Rhyme Used for the Study, recited over and over} for a total of 1 minute
a. Peter Piper Picked A Peck of Pickled Peppers
b. Peter Piper picked a peck of pickled peppers.
c. A peck of pickled peppers Peter Piper picked.
d. If Peter Piper picked a peck of pickled peppers,
e. Where's the peck of pickled peppers Peter Piper picked? 


\section{Results}

\section{Range of Colony counts}

a) 0 colony forming unit (CFU) to $>100 \mathrm{CFU}$. Of the 17 people tested reading the Rhyme without a mask, 16 showed growth. An average of 44-49 CFU were seen in the positive samples.
Organisms cultured, Staphylococcus sp., Micrococcus sp., streptococcus viridans group, Corynebacterium sp., Rothia mucilaginosa, Neisseria subflava

b) All are members of normal flora (Figure 1).

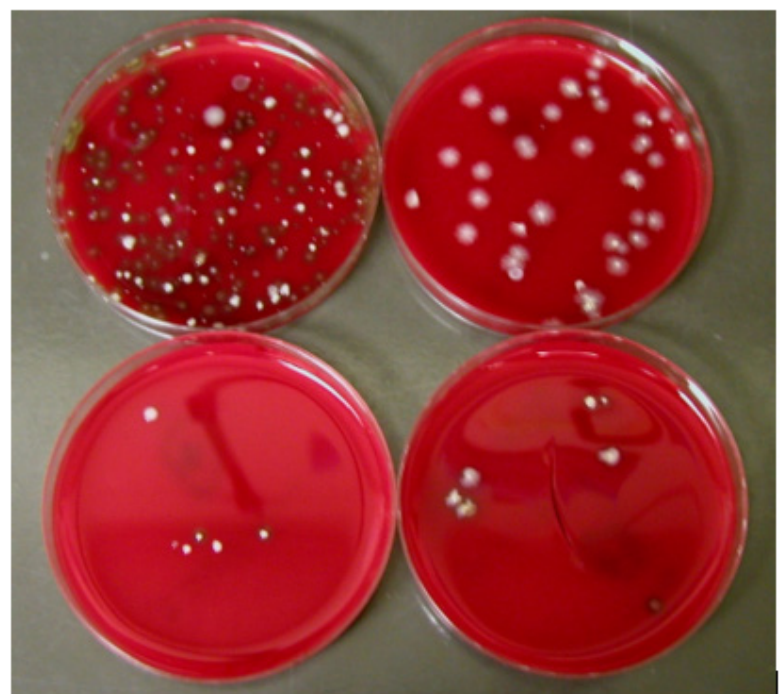

Figure 1: Top plates are from individuals reading the Nursery Rhyme without a mask, 12 inches away from the mouth.

Figure 1 plates on the bottom are from the same individuals reading the Nursery Rhyme and wearing a mask, 12 inches away from the mouth. Top and bottom left from the same individual without mask at the top and with a mask on the bottom. Top and bottom right from the same individual without mask at the top and with a mask on the bottom.

\section{Conclusion}

This study is important to re-enforce to the people in and out of the hospital the importance of barrier precautions in the during this time of a pandemic. Bacteria are ubiquitous and we should be on guard to prevent transmission from personnel to personnel. Also, droplet nuclei can aid in spreading viral infections as well. This is extremely important today to during this COVID pandemic that is transmitted though the upper respiratory tract $[3,4,6]$.

\section{References}

1. Scientific Brief: Community Use of Cloth Masks to Control the Spread of SARS-CoV-2 Accessed 1/25/2021.

2. How to protect Yourself \& Others. The Centers for Disease Control and Prevention.

3. Transmission of Sars-CoV-2: implications for infection prevention precautions. The World Health Organization.

4. Wei J, Li Y (2016) Airborne spread of infectious agents in the indoor environment. Am J Infect Control 44(9 Suppl): S102-S108.

5. Asadi S, Wexler AS, Cappa CD, Barreda S, Bouvier NM, Ristenpart WD (2020) Effect of voicing and articulation manner on aerosol particle emission during human speech. PLoS ONE 15(1): e0227699.

6. Jayaweera M, Perera H, Gunawardana B, Manatunge J (2020) Transmission of COVID-19 virus by droplets and aerosols: A critical review on the unresolved dichotomy. Environ Res 188: 109819. 